\title{
Origen de los manantiales de La Costa Verde
}

\author{
Rubén Rojas ${ }^{1}$, Modesto Montoya ${ }^{1,2}$, Enoc Mamani ${ }^{1}$, José Maguiña ${ }^{1}$, Eduardo Montoya ${ }^{1}$, Óscar Baltuano ${ }^{1}$, Patricia \\ Bedregal ${ }^{1}$, Lucy Coria ${ }^{2}$, Alcides Guerra ${ }^{3}$, Santiago Justo $^{3}$ y Tania Churasacari ${ }^{3}$ \\ ${ }^{1}$ Instituto Peruano de Energía Nuclear, Canadá 1470, San Borja, Lima, Perú \\ ${ }^{2}$ Facultad de Ciencias, Universidad Nacional de Ingeniería, Av. Túpac Amaru 210, Lima, Perú \\ ${ }^{3}$ Universidad Ricardo Palma, Av. Benavides 5440, Santiago de Surco, Lima, Perú
}

\begin{abstract}
Resumen
Este trabajo trata de determinar el origen los manantiales de la playa Costa Verde, situada en los distritos de Barranco, Miraflores y Magdalena de la provincia de Lima, Perú. Esos manantiales, cerca y a nivel del mar, sobreviven al proceso de urbanización de los terrenos de cultivo, iniciado en la década de los años 70 , el que mermó el nivel freático del acuífero de Lima, e hizo desaparecer las filtraciones de agua en los acantilados. Para identificar el origen se ha efectuado análisis isotópico, físico químico y bacteriológico de muestras tomadas de 5 manantiales. Los valores de conductividad y temperatura, determinados in situ, son similares a los obtenidos en aguas del acuífero de Lima. Los análisis en laboratorio no mostraron indicios significativos de coliformes fecales ni totales, descartando posibles filtraciones de la red de alcantarillado de Lima. Las concentraciones isotópicas del agua difieren del promedio de las obtenidas para las aguas del acuífero de Lima, recargado por infiltraciones del río Rímac. Estos resultados sugieren que las aguas de los manantiales de la Costa Verde provienen de una recarga directa en la cuenca media del río, producto de la infiltración del río o de precipitaciones a una altitud del orden de $3600 \mathrm{~m}$.
\end{abstract}

Descriptores: acuifero, agua, costa, Lima, Perú

\section{Abstract}

This paper tries to determine the origin of springs on the beach Costa Verde, located in the district of Barranco, Miraflores and Magdalena province of Lima, Peru. These springs, near and at sea level, survive the process of urbanization of agricultural land, started in the early 70 s, which decreased the water table aquifer of Lima, and wiped the water leaks into the cliffs. To identify the source isotope physical, chemical and bacteriological of samples taken from five springs analysis has been carried out. The conductivity and temperature, measured in situ, are similar to those obtained on Lima aquifer waters. The laboratory analysis showed no significant signs of total or fecal coliform, discarding possible leakage from sewerage Lima. The water isotopic concentrations on springs differ from the average obtained on Lima aquifer waters, recharged by infiltration of the Rimac River. 
These results suggest that the water from the springs of Costa Verde come from a direct recharge in the basin of the river, due to infiltration of rainfall or river at an altitude of about $3600 \mathrm{~m} .4226810$

Keywords: aquifer, water, coast, Lima, Peru

\section{Introducción}

Entre los 1989 y 1992, profesionales del IPEN y de la empresa encargada del abastecimiento de agua a Lima, SEDAPAL, con el auspicio y asesoramiento del Organismo Internacional de Energía Atómica (OIEA), llevaron a cabo estudios sobre el acuífero de Lima [1] y sobre el origen de las aguas del túnel Graton [2]. En estos estudios se aplicaron técnicas isotópicas, con el fin de obtener mayor información hidrogeológica para una mejor gestión de los recursos hídricos para la ciudad de Lima. Los análisis isotópicos fueron efectuados en los laboratorios del OIEA de Viena, Austria; y los análisis químicos se realizaron en los laboratorios de la empresa SEDAPAL. En estos estudios, i) se verificó que las aguas del acuífero de Lima provienen de la infiltración de los ríos Rímac y Chillón en la zona costera de sus cuencas, y se determinó sus respectivas áreas de recarga ii) se determinó que una parte de las aguas del túnel Graton proviene de infiltraciones de lluvias de la cuenca alta del rio Mantaro iii) se determinó la gradiente de altitud de concentraciones de ${ }^{2} \mathrm{H}$ y ${ }^{18} \mathrm{O}$ en precipitaciones de las cuencas de los ríos Rímac y Chillón.

El túnel Graton fue construido por la empresa Cerro de Pasco Corporation en los años 50 con fines de drenaje de las galerías de mina de Casapalca. Este túnel tiene una longitud de $12 \mathrm{~km}$; la boca, que se encuentra en la cuenca alta del río Rímac, tiene una cota de salida de $3200 \mathrm{msnm}$; y entrega un caudal que fluctúa entre 4 y $6 \mathrm{~m}^{3} / \mathrm{s}$ al río Rímac, el que junto al río Chillón y los más de 300 pozos perforados en el acuífero que administra la empresa SEDAPAL, abastecen de agua a Lima Metropolitana y el Callao, ciudades que juntas cuentan actualmente con una población de cerca de 10 millones de habitantes.

Por haber ocurrido frente a la playa, el proceso de extinción de manantiales de Lima ha sido más evidente en los acantilados de las playas de la Costa Verde, que es como se denomina al conjunto de playas de Barranco, Miraflores y Magdalena. Hasta los años 60 , los bañistas todavía los usaban como duchas al salir del mar. Ahora solo quedan algunos manantiales a nivel del mar. Parte de las aguas que drenan se usan para riego de jardines de la zona, y el resto se vierte directamente al mar.

En este trabajo se tratará de determinar el origen y la hidrodinámica de los manantiales remanentes de la playa Costa Verde. Para ello se efectuaron análisis isotópico, químico y bacteriológico.

\section{Análisis físico químico}

Las aguas de las playas Barranquito y La Estrella tienen una temperatura de $23{ }^{\circ} \mathrm{C}$ y $22.5{ }^{\circ} \mathrm{C}$, respectivamente; mientras que el agua del mar tiene una temperatura de $17.7^{\circ} \mathrm{C}$. El agua de Barranquito tiene una conductividad de $0.77 \mathrm{mS} / \mathrm{cm}$, y la de La Estrella $0.93 \mathrm{mS} / \mathrm{cm}$; mientras que la del mar tiene una muy alta conductividad que esta fuera del rango de medición del equipo. Ver Tabla 1.

\section{Análisis isotópico}

Los análisis isotópicos de las aguas de los manantiales de la Costa Verde fueron efectuados en los laboratorios del IPEN con el analizador isotópico de agua líquida LGR (de tecnología láser), con el que se determinó las concentraciones de los isótopos estables de ${ }^{2} \mathrm{H}$ y ${ }^{18} \mathrm{O}$ del agua, $\delta^{2} \mathrm{H}$ y $\delta^{18} \mathrm{O}$, respectivamente, de los manantiales estudiados. Los resultados de la concentración isotópica son expresados en valor $\delta$ en partes por mil (o/oo) referido a VSMOW (Vienna Standard Mean Ocean Water, patrón provisto por el OIEA). Los resultados son mostrados en la Tabla 2. 
Tabla 1: Parámetros físico químicos medidos en campo

\begin{tabular}{|l|r|r|}
\hline Manantial & $\begin{array}{r}\text { Conductividad } \\
\text { Eléctrica } \\
(\mathrm{mS} / \mathrm{cm})\end{array}$ & $\begin{array}{r}\text { Temp } \\
(\mathrm{C})\end{array}$ \\
\hline Barranquito & 0.77 & 23 \\
\hline Estrella & 0.93 & 22.5 \\
\hline Mar & $\begin{array}{r}\text { Muy alta, } \\
\text { fuera de } \\
\text { rango del } \\
\text { equipo }\end{array}$ & 17.7 \\
& \\
\hline
\end{tabular}

En la Fig. 1 se ha graficado los valores $\delta^{2} \mathrm{H}$ vs $\delta^{18} \mathrm{O}$ de la Tabla 2 junto a los obtenidos en el año 1990. Se puede apreciar que los valores de $\delta^{2} \mathrm{H}$ de los manantiales de las playas de la playa Costa Verde están entre -101.92 o/oo y -108.31 o/oo y los de $\delta^{18} \mathrm{O}$ están entre -14.41 o/oo y -15.41 o/oo.

Tabla 2: Valores de las concentraciones ( $\delta)$ de ${ }^{2} \mathrm{H}$ y ${ }^{18} \mathrm{O}$ y desviaciones estándar $(D E)$ de las aguas de manantiales de La Costa Verde (compuesta por playas de Barranco, Miraflores y Magdalena de Lima, Perú); de Huarangal en la cuenca del río Chillón, y del distrito de Villa María del Triunfo, efectuadas en noviembre y diciembre del 2012.

\begin{tabular}{|l|l|l|l|l|}
\hline Origen & $\begin{array}{l}\delta^{2} \mathrm{H} \\
\text { Valor } \\
(0 / 00)\end{array}$ & $\begin{array}{l}\delta^{2} \mathrm{H} \\
\mathrm{DE} \\
(0 / 00)\end{array}$ & $\begin{array}{l}\delta^{18} \mathrm{O} \\
\text { Valor } \\
(0 / 00)\end{array}$ & $\begin{array}{l}\delta^{18} \mathrm{O} \\
\mathrm{DE} \\
(0 / 00)\end{array}$ \\
\hline Barranquito & -104.73 & 0.39 & -14.60 & 0.19 \\
\hline Huarangal 1 & -96.36 & 0.59 & -13.01 & 0.03 \\
\hline Huarangal 2 & -95.56 & 0.87 & -13.00 & 0.07 \\
\hline La Estrella & -104.63 & 0.24 & -14.41 & 0.14 \\
\hline Paraiso1 & -96.13 & 0.53 & -13.76 & 0.19 \\
\hline Barranquito & -101.92 & 1.64 & -14.67 & 0.24 \\
\hline La Estrella & -102.77 & 0.36 & -14.78 & 0.15 \\
\hline Los Yuyos & -105.83 & 1.31 & -14.63 & 0.07 \\
\hline Barranquito & -108.31 & 0.09 & -15.01 & 0.05 \\
\hline La Estrella & -105.42 & 0.73 & -15.41 & 0.14 \\
\hline La Estrella & -103.07 & 1.25 & -14.51 & 0.06 \\
\hline Agua Dulce & -102.33 & 1.16 & -14.51 & 0.16 \\
\hline Barranquito & -102.70 & 1.42 & -14.80 & 0.17 \\
\hline Magdalena & -104.86 & 1.09 & -14.64 & 0.12 \\
\hline
\end{tabular}

Nota: Resultados expresados en $\delta(0 / 00)$ (delta por mil) referido al estándar VSMOW.
Estos valores muestran un desplazamiento del promedio de concentraciones isotópicas del $\delta^{2} \mathrm{H}$ y $\delta^{18} \mathrm{O}$ obtenido en los análisis isotópicos efectuados en el acuífero de Lima entre 1989 y 1990 en el sector recargado por el rio Rímac (-102.9 y -13.97, respectivamente), hacia un sector que indica el empobrecimiento isotópico de las aguas, y sugiere proviene de una recarga directa de filtraciones de precipitaciones ocurridas en una zona ubicada a una altitud promedio del orden de $3600 \mathrm{msnm}$, según la Gradiente de Altitud isotópica determinada con la información de los años 1989 y 1990.

Los valores de muestras del manantial MHUA1 y MHUA2 ubicados frente al Centro Nuclear de Huarangal, son compatibles con las características de aguas de la cuenca del rio Chillón al que pertenece. Las aguas de los manantiales de Villa María del Triunfo (sur de Lima) muestran un origen diferente al resto que requiere estudios adicionales.

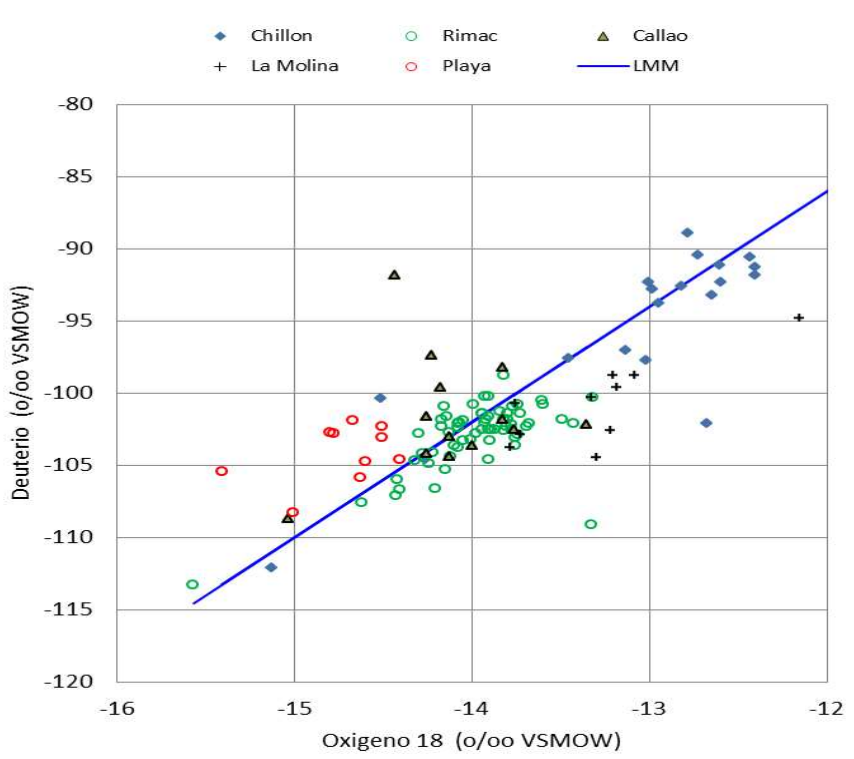

Fig. 1: Isotopos estables de aguas del acuífero de Lima y de manantiales de la Costa Verde

\section{Análisis bacteriológico}

Los análisis bacteriológicos fueron llevados a cabo en los laboratorios de la Facultad de Ciencias Biológicas de la Universidad Ricardo Palma. 
Para la determinación del total de coliformes se ha usado la técnica estándar por fermentación 9221B para el análisis de agua y desagüe [3]. Los resultados son presentados en la Tabla 3. Los coliformes son 7 por $100 \mathrm{ml}$ para el manantial de Barranquito y 13 por $100 \mathrm{ml}$ para el manantial de la playa Estrella.

El número de coliformes fecales se ha medido con el procedimiento 9221E para el análisis de agua y desagüe [3]. No se ha detectado coliformes fecales en ninguno de los dos manantiales analizados cuando no hay riesgo de contaminación por bañistas.

Tabla 3: Número más probable (N.M.P.) de coliformes (totales y termotolerantes) y recuento de heterotróficos $(H)$ de aguas de los manantiales de La Costa Verde (realizados en diciembre del 2012 y febrero 2013). Para comparación se analizó aguas de un pozo y un manantial del distrito de Villa María del Triunfo (Sur de Lima).

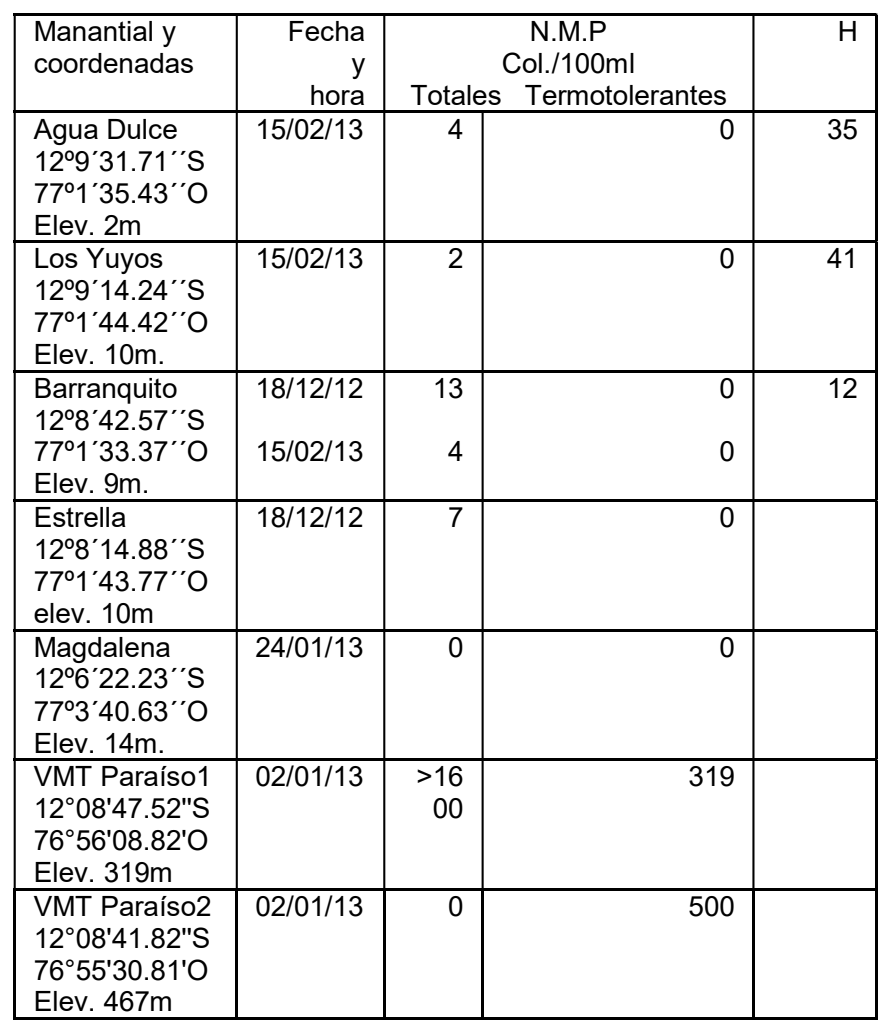

La contaminación por Escherichia coli se medido por el método estándar para el análisis de agua y desagüe $9221 \mathrm{~F}$ [3]. No se encontraron evidencias de contaminación bacteriológica en aguas de los acuíferos de la playa Costa Verde, pero si en las muestras de aguas de Villa Maria del Triunfo, donde se determinó que el total de coliformes es de 1600 y el número de coliformes fecales es de 319 por 100 $\mathrm{ml}$.

La diferencia en el nivel de contaminación orgánica de los manantiales de la playa Costa Verde y de los de Villa María del Triunfo, sugiere que estos últimos atraviesan zonas contaminadas cercanas a la superficie, debido a la alta densidad de población con limitados servicios de agua y desagüe que caracterizan la zona.

En los laboratorios de química analítica del IPEN se midió los contenidos de plomo, cadmio, mercurio y arsénico en las aguas de los manantiales de Villa María del Triunfo. Se usó la técnica de "Square Wave Anodic Stripping Voltammetry" (SWASV). Los contenidos de plomo, cadmio, mercurio y arsénico resultaron, respectivamente, menores a 2 microgramos por litro.

\section{Conclusiones}

Los análisis isotópicos de aguas de los manantiales de la Costa verde de los distritos Miraflores y Magdalena de la provincia de Lima, Perú, sugieren que tienen una hidrodinámica un tanto diferente del acuífero de Lima, y provienen de filtraciones de precipitaciones ocurridas en zonas ubicadas a una altitud promedio del orden de $3600 \mathrm{msnm}$.

El bajo o nulo número coliformes fecales y coliformes totales en muestras tomadas el mes de diciembre, antes de la temporada veraniega, refuerzan esta hipótesis. Los resultados mostrados son preliminares y requieren análisis de mayor cantidad de muestras en diversos periodos del año, así como análisis de los tiempos de residencia. 


\section{Agradecimientos}

Agradecemos a Wilfredo Cardenas Sulca, estudiante de Ingenieria Ambiental, y Dario Ccaccya Ccaccya, estudiante de Ingenieria Ambiental, ambos de la Universidad Nacional Tecnológica del Cono Sur de Lima (UNTECS), por haber ubicado y habernos guiado a los manantiales Paraíso del distrito de Villa María del Triunfo, y por su labor de promoción de la preservación de la biodiversidad en la zona.

\section{Referencias}

[1] J.C. Ruiz y R. Rojas Molina. Estudio hidrológico del acuífero de Lima (Perú) aplicando técnicas isotópicas, Estudios de Hidrología Isotópica en América Latina 1994. IAEA TECDOC - 635, Organismo Internacional de Energía Atómica, octubre 1995.

[2] A. Plata Bedmar y R. Rojas Molina. Origen de las aguas que drena el túnel Graton. Informe OIEA. INIS-PE-95-02, 1995
[3] Standard Methods for the examination of water and wastewater 21 st Edition 2005

Email: rrojas@ipen.gob.pe,

modesto_montoya@yahoo.com 